アルカリ㚭理オゴノリ寒天の 抽出条件と物性*

平光 武**・原田典宜 ${ }^{* *} \cdot$ 林 金雄:**

Physical Properties of Agar prepared from Alkali-treated Ogonori (Gracilaria verrucosa)

Takeshi Hiramitsu, Noriyoshi Harada and Kaneo Hayashi

Ogonori (Gracilaria verrucosa) is now considered to be one of the most valuable raw material seaweed of agar industry in Japan. In order to obtain information on the effect of treatment, the alkali treatment of ogonori and preparation of agar from it. was carried out under various conditions. Yield and total $\mathrm{SO}_{3}$ of agar and physical properties such as jelly strength, load deformation, melting point and syneresis of agar gel were measured.

(Received July 3, 1970)

わが国ではアルカリ処理オゴノリ寒天は年間約 800 卜 ン生産されていて，寒天全生産量の約 $30 \%$ にあたる。 そのうち岐阜県の生産は約 400 トンに達している。

近年フルカリ処理について研究が進みつつあるが流, なお究明すへき点が多いので，国内でもっとも生産量の 多い北海道厚岸産オゴノリについて，アルカリ処理条件 と抽出調製された寒天の物性との関係を調べた。

\section{1. 供試原藻}

オゴノリ $(\mathrm{A}): 1968$ 年に北海道厚岸で採取された風 乾オゴノり(Gracilaria verrucosa)で, 北海道漁連検査 等品。

供試才ゴノりを水洗後風乾して水洗オゴノリとした。 収率 $48 \%$ (対風乾原藻無水物), 全 $\mathrm{SO}_{8} 3.5 \%$ (林ら ${ }^{2}$ )の 方法による。対水洗原澡無水物)

オゴノリ(B): 1969 年北海道厚岸で採取された風乾才 ゴノリで, 北海道漁連検查 1 等品。

マクサ：1969 年伊豆下田で採取されたマクサ（Gelidium amansii) で，水洗後風乾して使用した。

*岐阜県における寒天製造に関する化学的研究（第 34 報)

***岐阜県寒天研究所（岐阜県恵那郡山岡町） Gifu Research Institute of Agar. Yamaoka, Ena, Gifu.

****忮阜大学農学部 (岐阜䍗各務原市那加門前町) Faculty of Agriculture, Gifu University. Kakamigahara, Gifu.

\section{2. オゴノリから寒天の調製}

水洗オゴノリ(A) $100 \mathrm{~g}$ に水 $3 l$ を加え，オートクレ ープ中で 90 分加圧抽出を行なった。所要気圧になるま での時間は 40 分, 所要気压から常圧になるまでの時間 は30 分とした。足立瀻維製沪布（ナイロンNF 1001）を 使用して压搾沪過した。得られた寒天ゲルを細寒天製造 用の天筒に入れて天突きしたものを， $-7^{\circ} \mathrm{C} \sim-15^{\circ} \mathrm{C}$ の 冷蔵庫中で, $-7^{\circ} \mathrm{C}$ で 3 時間, つぎに $-15^{\circ} \mathrm{C}$ で 20 時 間放置して完全に凍結させた。これを日中とり出して天 日によって自然融解させ，2３日間風乾して寒天を得 た。結果を第 1 表に示した。

\section{3. アルカリ処理}

アルカリ処理オゴノリ（A)：供試オゴノリ(A) $100 \mathrm{~g}$ に第 2 表に示した $\mathrm{NaOH}$ 液 $2 l$ を加え, 20 分で $85^{\circ} \mathrm{C}$ としこの温度で 2 時間処理してから，布で沪別，水洗後 さらに 1 時間流水に浸漬した。次に第 2 表に示した $\mathrm{HCl}$ に 1 時間浸漬して中和し，さらに流水中で約 2 時間执よ び水中で 1 夜浸漬した。水穵切って風乾した。その収率 と全 $\mathrm{SO}_{3}$ を第 2 表に示した。

フルカリ処理オゴノリ（B)：供試オゴノリ（B)を $5 \%$ $\mathrm{NaOH}$ で $80^{\circ} \mathrm{C} \sim 85^{\circ} \mathrm{C} \cdot 3$ 洔間処理し, 上記同様風乾し た。その全 $\mathrm{SO}_{3}$ は $1.9 \%$ (対アルカリ処理オゴノリ無 水物)

4. アルカリ処理オゴノリから寒天の調製

林らの方法 ${ }^{5}$ に準じてアルカリ処理オゴノリ(A) $10 \mathrm{~g}$ を, $1 \mathrm{~N} \mathrm{H}_{2} \mathrm{SO}_{4} 1 \sim 3 \mathrm{ml}$ 老添加した $500 \mathrm{ml}$ の水で劣 熟抽出して寒天を調製して，物性を測定した結果を第 2 㤗に示した。

アルカリ処理によって処理オゴノリの収率は減少する が, $\mathrm{NaOH}$ 濃度 2〜9\% ではほぼ一定の $55 \%$ である。 アルカリ処理原藻に対する寒天の収來は $\mathrm{NaOH}$ 濃度が

第 1 表 オゴノリがら調製した寒天

\begin{tabular}{|c|c|c|c|c|c|}
\hline $\begin{array}{l}\text { 加正条件 } \\
\text { (気压) }\end{array}$ & $\begin{array}{c}\text { 収种1 } \\
(\%)\end{array}$ & 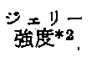 & 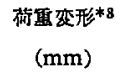 & $\begin{array}{l}\text { 蚱点*4 } \\
\left({ }^{\circ} \mathrm{C}\right)\end{array}$ & 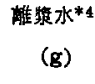 \\
\hline 1.0 & 30 & 12 & 11 & 81.0 & 0.3 \\
\hline 1.5 & 35 & 9 & 10 & 78.0 & 0.5 \\
\hline
\end{tabular}

*1 対水洗原莎整水物 \%

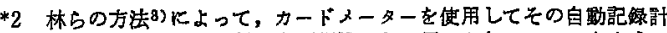

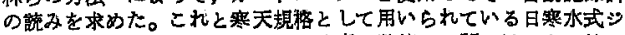

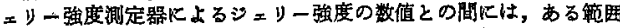

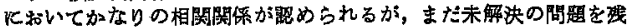

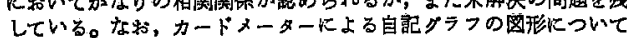
は，その测定方法とともに研究の余地が多いので䯆及することをさ しひかえた。

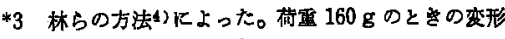

*4林らの方法らによった。 
高くなるにつれて多くなる傾向が見られるが，いっぽう 水洗原藻に対する寒天の収率は $\mathrm{NaOH}$ 浱度にはほとん ど関係しない。たたこし $\mathrm{NaOH}$ 濃度の低い場合に寒天収 梁が低いが，これは凍結乾燥時における寒天および水溶 性多糖類の流失によるものと考えられる。これらのとと からフルカリ処理によって除去される部分は寒天の収率 にあまり影響しないと考えられる。

フルカリ処理によって寒天のジェリ一強度は増大寸る $\dddot{~} \mathrm{NaOH}$ 濃度があまり高くなると逆に減少する傾向を 示与。処理オゴノリの全 $\mathrm{SO}_{3}$ は $\mathrm{NaOH}$ 浱度の增加に伴 って減少する。ある籁团内ではこの $\mathrm{SO}_{3}$ 量とジェリ一強 度との間に相関関係があると推定できる。この場合多糖 類に結合している $\mathrm{SO}_{3}$ 基の脱離と寒天分子の破塤とい う点を考虑すべきであろう。

荷重变形は $\mathrm{NaOH}$ 濃度 $2 \%$ までは急速に減少しその 後はアルカリの䀼度の上昇に伴なって徐々に減少してい て, 処理オゴノリの全 $\mathrm{SO}_{3}$ と相関関係がある。他方融 点はジェリ一強度と, 離漿水は荷重変形とほぼ同じ傾向 を示したがこれらの物性は抽出条件によってかなり影 䪪を受けるので今後の検討が必要である。
なお全 $\mathrm{SO}_{8}$ の多い処理オゴノリからの寒天は凍結乾 懆が困難であったが，これは $\mathrm{SO}_{3}$ が親水性であるため であらう。

フルカリ処理オゴノリの全 $\mathrm{SO}_{8}$ と，それから調製し た寒天の物性との間には密接な関倸があるので，フルカ リ処理の適否を推定する有力な手段となりうる。本実験 条件下では $\mathrm{SO}_{8}$ が $1.7 \%$ 程度なれば適当と思われる。

5. 抽出条件と寒天の物性

（1）常生抽出：水 $500 \mathrm{~m} l$ を電熱器上で加熱沸騰さ せ, これに適当量の $1 \mathrm{~N} \mathrm{H}_{2} \mathrm{SO}_{4}$ を添加して，すぐフル カリ処理オゴノリ(B) $10 \mathrm{~g}$ を加光，適当時間孠した。

(2) 加圧抽出：水 $500 \mathrm{~m} l$ K適当量の $1 \mathrm{~N} \mathrm{H}_{2} \mathrm{SO}_{4}$ を 加皃たなかに (1) と同様に原藻を入れて，オートクレー ブ中で 1 2 気圧・ 45 分煮熟した。

以上の 2 方法で煮熟後, 前記と同样に汇過・凍結・融 解・乾燥を行なって寒天を調製した。

寒天収率と物性測定結果を第 3 表に示した。

アルカリ処理オゴノリはアルカリ性であり, 添加硫酸 澴度が高いほど早く中和されて寒天が早く抽出される。 抽出条件によって寒天収率は影響をうける。寒天のジェ

第 2 表 ナルカリ処理オゴノリ（A）およびこれから調製した寒天

\begin{tabular}{|c|c|c|c|c|c|c|c|c|c|c|c|}
\hline \multicolumn{4}{|c|}{ フルカリ処理オゴリ（A) } & \multicolumn{8}{|c|}{ アルカリ始理オゴノリ（A）から制製した寒天 } \\
\hline $\begin{array}{r}\text { 好 理 } \\
\mathrm{NaOH}(\%)\end{array}$ & $\begin{array}{l}\text { 条 件 } \\
\mathrm{HCl}^{* 1}(\%)\end{array}$ & $\begin{array}{l}\text { 收卒*2 } \\
(\%)\end{array}$ & $\begin{array}{c}\text { 全SOg*3 } \\
(\%)\end{array}$ & $\begin{array}{r}\text { 拈出条 } \\
1 \mathrm{NH}_{2} \mathrm{SO}_{4}(\mathrm{~m} l)\end{array}$ & $\begin{array}{l}\text { 件 } \\
\text { 嚾最*4 }\end{array}$ & $\begin{array}{l}\text { 収 } \\
A^{* 5}\end{array}$ & $\begin{array}{l}\text { 畜 } \\
\text { B }^{* 6}\end{array}$ & $\begin{array}{l}F=y- \\
\text { 强度*7 }\end{array}$ & $\begin{array}{c}\text { 倚薑变形*7 } \\
(\mathrm{mm})\end{array}$ & 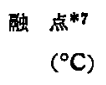 & $\begin{array}{c}\text { 離饿水*7 } \\
(g)\end{array}$ \\
\hline 0.5 & 0.02 & 61 & 3.4 & 1 & 困 難 & 33 & 20 & 18 & 8.9 & 77.5 & 0.63 \\
\hline$\prime \prime$ & $" \prime$ & $" \prime$ & $" \prime$ & 2 & 11 & 38 & 23 & 13 & 11.2 & 76.0 & 0.74 \\
\hline 1.0 & 0.02 & 56 & 2.9 & 1 & p户困嚾 & 44 & 25 & 18 & 8.8 & 78.0 & 0.62 \\
\hline$\prime \prime$ & $\prime \prime$ & $\prime \prime$ & $\prime \prime$ & 2 & $\prime \prime$ & 48 & 27 & 15 & 8.5 & 72.0 & 0.75 \\
\hline 2.0 & 0.03 & 56 & 2.3 & 1 & 容 易 & 45 & 25 & 30 & 3.7 & 80.5 & 0.51 \\
\hline$" \prime$ & $" \prime$ & $" \prime$ & $\prime \prime$ & 2 & $\prime \prime$ & 50 & 28 & 26 & 3.4 & 76.0 & 0.60 \\
\hline 3.0 & 0.04 & 56 & 2.1 & 1 & $" \prime$ & 43 & 24 & 53 & 2.4 & 82.0 & 0.49 \\
\hline$" \prime$ & $" \prime$ & $" \prime$ & $" \prime$ & 2 & "I & 50 & 28 & 45 & 2.4 & 77.5 & 0.51 \\
\hline 4.0 & 0.05 & 55 & 1.9 & 1 & $\prime \prime$ & 44 & 24 & 65 & 2.2 & 81.5 & 0.46 \\
\hline " & $\prime \prime$ & $\prime \prime$ & $" \prime$ & 3 & $" \prime$ & 56 & 31 & 42 & 2.0 & 76.0 & 0.54 \\
\hline 5.0 & 0.06 & 55 & 1.7 & 1 & $" \prime$ & 43 & 24 & 77 & 1.9 & 86.0 & 0.43 \\
\hline$\prime \prime$ & $\prime \prime$ & $\prime \prime$ & $\prime \prime$ & 3 & $" \prime$ & 58 & 32 & 50 & 1.8 & 81.5 & 0.52 \\
\hline 7.0 & 0.07 & 55 & 1.7 & 1 & $\prime \prime$ & 47 & 26 & 76 & 1.8 & 85.0 & 0.46 \\
\hline$" \prime$ & $" \prime$ & $\prime \prime$ & $" \prime$ & 2 & $" \prime$ & 56 & 31 & 55 & 1.6 & 81.0 & 0.54 \\
\hline 9.0 & 0.08 & 55 & 1.6 & 1 & 11 & 46 & 25 & 64 & 1.7 & 84.0 & 0.49 \\
\hline$\prime \prime$ & $\prime \prime$ & $"$ & $\prime \prime$ & 2 & $" \prime$ & 60 & 33 & 48 & 1.5 & 80.0 & 0.58 \\
\hline
\end{tabular}

*1 中和用

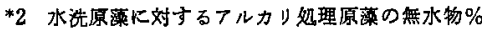

*3 フルカリ処理原䔯に対する無水物\%

*4 瑓結䩐燥の嚾易
*5 フルカリ処理原藻に対する収率（無水物\%)

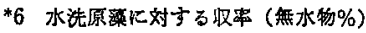

*7 第 1 表と同し 
第 3 表 アルカリ処理オゴノリ (B)から寒天の調製

\begin{tabular}{|c|c|c|c|c|c|}
\hline 抽 & 条 & 件 & & & \\
\hline $1 \mathrm{NH}_{2} \mathrm{SO}_{4}(\mathrm{ml})$ & 任 & 尜焏時間 (分) & 收率*1 (\%) & $\because \times リ ー$ 强度*2 & 触点*2 $\left({ }^{\circ} \mathrm{C}\right)$ \\
\hline 4 & 常 E & 60 & 24 & 98 & 96.5 \\
\hline 5 & $\prime \prime$ & 60 & 29 & 87 & 95.0 \\
\hline$"$ & $"$ & 150 & 36 & 91 & 83.5 \\
\hline 6 & $" \prime$ & 60 & 34 & 77 & 91.0 \\
\hline$"$ & $" \prime$ & 90 & 42 & 79 & 89.5 \\
\hline$\prime$ & $" \prime$ & 120 & 42 & 83 & 89.0 \\
\hline$"$ & $" \prime$ & 150 & 43 & 100 & 88.5 \\
\hline 7 & $"$ & 60 & 43 & 70 & 87.5 \\
\hline " & " & 90 & 48 & 71 & 86.5 \\
\hline$n$ & $\prime \prime$ & 120 & 49 & 68 & 86.0 \\
\hline$\prime \prime$ & $\prime \prime$ & 150 & 51 & 64 & 85.0 \\
\hline 8 & " & 30 & 54 & 50 & 82.0 \\
\hline$"$ & $"$ & 60 & 56 & 55 & 82.0 \\
\hline 1 & $1.0 \pm 0.1$ & $45^{* 3}$ & 12 & 100 以上 & 97.5 \\
\hline 2 & $"$ & $"$ & 14 & " & $" \prime$ \\
\hline 3 & " & $"$ & 18 & $"$ & 96.5 \\
\hline 4 & " & $"$ & 28 & 99 & 93.5 \\
\hline 5 & $" \prime$ & $" \prime$ & 41 & 85 & 88.5 \\
\hline 6 & "I & " & 50 & 66 & 85.0 \\
\hline
\end{tabular}

*1 フルカリ処理オゴノにに付する収密（無水物％)

*2 第1麦と同じ

*3 加压加熱時間

リー強度も抽出条件によって影䇾をうけるが，ジェリー 強度と収率とではその最高点ば一致しない。寒天の融点 も抽出条件によって影響をうける。

$$
\text { 文献 }
$$

1）林 金雄・岡崎彰夫：寒天ハンドブック（光琳書 院), p. 278, 399 (1970).
2) 林 金雄・平光 武・中村武司：震伦，43，699 (1969).

3）林 金雄 - 平光 武：食品工誌, 16, 160 (1969).

4）林 金雄 - 平光 武：食品工誌, 16, 162 (1969).

5）林 金雄-原田典宜・平光 武：食品工誌, 16, 315 (1969).

(1970 年 7 月 3 日受理) 